\title{
Knowledge Management Practices among the Internal Quality Assurance Network (IQAN)-Member Higher Education Institutions (HEIs) in Thailand
}

\author{
Esther Funmilayo Zinzou ${ }^{1} \&$ Teresita Rubang Doctor ${ }^{1, *}$ \\ ${ }^{1}$ Faculty of Education, St. Theresa International College, Nakhon Nayok, Thailand \\ *Correspondence: Faculty of Education, St. Theresa International College, Ongkarak, Nakhon Nayok, Thailand. Tel: \\ 66-966-570-379. E-mail: tessdoctor@gmail.com
}

Received: August 17, 2020

Accepted: September 8, $2020 \quad$ Online Published: October 18, 2020

doi:10.5430/wje.v10n5p108

URL: https://doi.org/10.5430/wje.v10n5p108

\begin{abstract}
Knowledge management is one of the essential processes in every organization because knowledge is recently considered an important asset that needs to be managed. However, in Thailand, it was observed that in many organizations more importantly the academe, knowledge management processed are not yet at fully implemented and employees are not really fully aware of the KM processes in their workplace.

This research reviewed the status of knowledge management (KM) in the IQAN- member college and universities in Thailand based on the interpretation of the practice of their rank and file staff. This study was able to find out the majority of the staff know about KM and view it as essential and strategic part of their institutions. They consider their HEIs as knowledge -based. Furthermore, most of the staff believe that KM in the HEIs are still in introductory, intermediate and some consider that KM is their institution is its growth stage and rated differently their institutes' KM practice from adequate, good to very good. The staff also affirmed that there is knowledge creation, storage, sharing and transfer via various modes. However, in the preference of use of technology tools, the rank and file staff least prefer the usage of the technology in KM management and prefer the use of communities of practice in the sharing of knowledge. It is therefore, strongly recommended that there should be continuous and cyclic process in $\mathrm{KM}$ wherein review of the different stages will be done regularly to update the staff especially in the use of technology because it is a very important tool in knowledge storage and sharing or communicating knowledge.
\end{abstract}

Keywords: knowledge management practices, rank and file staff, Internal Quality Assurance Network (IQAN), member- higher educational institutions, Thailand

\section{Introduction}

Knowledge management $(\mathrm{KM})$ is the effective use of information and resources within an organization. It is the process of creating, sharing, using and managing the knowledge and information of an organization. It refers to a multidisciplinary approach to achieving organizational objectives by making the best use of knowledge (Girard \& Girard, 2015) In addition, Gartner Group (2005) KM as a discipline that promotes an integrated approach to identifying managing and sharing of all of an enterprise's information assets. These information assets may include database documents, policies procedures as well as previously unarticulated expertise and experience resident in individual workers. Knowledge management issues include developing, implementing and maintaining the appropriate technical and organizational infrastructure to enable knowledge sharing.

In recent years, knowledge management (KM) has received increased attention from academics and practitioners. According to Kidwell, Linde \& Johnson (2004), using knowledge management techniques and technologies in higher education is as vital as it is in the corporate sector because the ability to manage knowledge is becoming increasingly more crucial in today's knowledge economy. The creation and diffusion of knowledge have become even more important factors in competitiveness (Nonaka \& Peltokoji, 2006). Dhamdhere (2015) mentioned that knowledge management is becoming popular in the field of education due to the need to disclose the intellectual power available in institutions. Although knowledge is increasingly being viewed as a commodity or an intellectual asset, it possesses some paradoxical characteristics that are radically different from those of other valuable 
commodities (Dasgupta, 2011). The advent of the Internet and the World Wide Web has made unlimited sources of knowledge available to us all. Thus, a knowledge management system is needed as virtual repository for relevant information which is critical to tasks performed daily by organizational knowledge workers. Historically, knowledge has always been managed, at least implicitly. However, effective and active knowledge management requires new perspectives and techniques and touches on almost all facets of an organization.

Despite all available media, both through the internet or manual handling of knowledge, the success of any organization depends on how effective the passed on knowledge is being executed. According to Alavi and Leidner 2001; Pentland, 1995, there are four knowledge processes and the problem can emanate from any of them are knowledge creation, knowledge storage also known as organizational memory, knowledge transfer and knowledge application. Many industries claim to practice knowledge management however, the educational institutions are also joining the band wagon thus this research focused on the review of the process by which knowledge management is being practiced in selected higher educational institutions. This will give an idea on how educational institutions manage the KM process. Thus, this also gives light on the best practices and weaknesses of implementation for further improvement in the higher educational institutions under study.

According to Petrides and Nodine (2003) the use of knowledge management method in education enables the encouragement of the greater intelligence, practical know-how, and effectiveness of education institution management. Knowledge management in education also offers the superiority of practical assessment framework that depends on the effectiveness of information management. In Addition, Rowley (2000) noted organizations that are knowledge-based mostly gain from it but needs significant change in the culture and values. Similarly, Biloslavo and Trnavcevic (2007) expressed the importance of KM in higher education. Dawson (2000) expressed that KM is especially important for organizations, comprised of experts where success depends upon generation, utilization and uniqueness of knowledge base. It would seem to be appropriate to consider higher educational institutions as organizations comprised of experts who contribute to knowledge base.

\subsection{Related Literature and Related Studies}

In the early 1990's, knowledge management became a scientific discipline supported by scholars, practitioners in corporate organizations and consultants, the application varies based on who is handling it per time. The three (3) major theories are the following: Organizational KM theory focuses on organizational structures, also known as the totality of values and norms in an organization that have been developed over time, they are accepted by the organizational members and have an influence on the creation, sharing and usage of knowledge (Grolik, 2004). In other words, he set of rules norms and practices adopted by an organization over a period of time becomes a culture, it could have been created by a group of people but it reflects the true identity, mission and vision of the organization, it is often passed down from one generation of employee to the other. Ecological KM theory focuses on people and relationships, interactions among individuals and organizations harnessing both internal and external factors that draw people together to share knowledge. This is created per time because no two people are the same, it is mostly instantaneous and subject to change putting into consideration the group of people working together per time. Techno-centric KM theory focuses on technology formation and design processes that help facilitate knowledge flow and storage. As the world changes, technologies also advance and this calls for constant reformation of knowledge management strategies in relation to technologies.

From the above mentioned theories, this research seek to establish the existing knowledge management practices in institutions selected for this research, this will help to further narrow down where the problem lies and how to propose a lasting and effective model that will cut across major aspect and individuals. Specifically, this study sought answers to the following questions: What is the status of knowledge management in the IQAN member -HEIs in Thailand? What are the implementation practices in terms of culture, training, policies, strategies/practices and technologies? What are the best practices and weaknesses in implementation policies? What model can be proposed for the implementation of $\mathrm{K}$ practices.

Some related studies were reviewed to support the findings of the study. Maponya, P. M. (2000) in a study entitled, Knowledge management practices in academic libraries: a case study of the University of Natal, Pietermaritzburg Libraries, concluded that people gain knowledge from their experiences and their peers' expertise. Cranfield and Taylor (2008) studied seven universities in UK for application of knowledge management. The researchers concluded that HEI leadership is slowly prioritizing KM and 21 st century management tools. The nature of academic staff and perceptions of the academic job have a direct impact on the culture of the institution and impose their own factors that contribute to the ability to adopt KM as a management tool; Evidence of the benefits of explicitly adopting KM principles within this context needs to be clearly understood by individual researchers and academics, 
as well as the administrators; The taxonomy for the application of KM within the HEI context should be considered; The management structure of a university affects its ability to respond quickly to external influences and pressures. Pircher and Pausits (2011) in their paper entitled Information and Knowledge Management (IKM) at HEIs concluded that IKM at HEIs is more the result of problem- oriented and decentralized IT development than a reflection of a strategic IT direction. Information management and the deployment of existing technologies to support the HEI are predominantly driven by administrative rather than management, executive or service-oriented needs. Furthermore, they mentioned that IT infrastructure that adequately handles all the institutional processes and administrative functions is essential for a university to function as an integrated whole, and that also supports strategic decision-making by management. Mládková (2011) conducted a study on Knowledge Management for Knowledge Workers in organizations in the Czech Republic The results of research found out that organizations in the Czech Republic do not create an environment and knowledge management systems supportive for their knowledge workers. Forty (44\%) of organizations that participated in research reported a top-down organizational structure that inhibits knowledge sharing and knowledge management activities. Ramakrishnan and Yasin (2012) studied Knowledge Management System (KMS) and Higher Education Institutions. This study explored such uses of Knowledge Management System in Higher Education Institution a public university in Malaysia. It was concluded that there is a need for KMS technology and systems to bridge the gap between present and prior contexts of knowledge creation, sharing, or application. KMS activities which are created for encouraging KMS processes must be in agreement with the organization's goals, social processes, organization behaviour, and organization strategy. To improve HEI performance and productivity, knowledge management system should be properly developed within HEI. Pinto (2014) in a paper entitled, Knowledge management in higher education institutions: A framework to improve collaboration, presented a framework that increases knowledge sharing and collaboration in Higher Education Institutions. The paper discussed the concept of knowledge management in higher education institutions, presenting a systematization of knowledge practices and tools to linking people (students, teachers, researchers, secretariat staff, external entities) and promoting the knowledge sharing across several key processes and services in a higher education institution, such as: the research processes, learning processes, student and alumni services, administrative services and processes, and strategic planning and management. The framework purposed in this paper aims to improve knowledge practices and processes which facilitate an environment and a culture of knowledge collaboration, sharing and discovery that should characterize an institution of higher education. Dhamdhere (2015) concluded in her study, Knowledge management applications and status in Indian education system: a survey, that new knowledge is generated from existing and past knowledge. The generation of knowledge is mainly from human efforts which are developed through conducting good educational activities, research activities and generating innovative concepts in the area of interest. All knowledge generating organizations like industries, R and D centers, and higher education academics from colleges to universities are in search of new concepts in their subject of interest and also contribute to knowledge through various means. These colleges and universities are considered as "Knowledge Houses" where knowledge flows from teachers to students and new knowledge is created. Though developed countries has already started knowledge management practices in educational and research institutes still many developing countries yet to start practicing this KM process. Charles, W. and Nawe, J. in the study, Knowledge Management (KM) Practices in Institutions of Higher Learning in Tanzania with Reference to Mbeya University of Science and Technology, it was found out that there was no practice of knowledge management in the said institution and recommended that it should be an integral part of the institution

\section{Method and Materials}

- A Quantitative-survey method was used in this study where in a self- report by the one hundred sixty five (165) rank and file staff was done on the KM practices of the IQAN-member HEIs in Thailand Namely: St Theresa International College, Asia Pacific University, Rangsit University, and Stamford University in Thailand.

- The research instrument in the form of a questionnaire which was adopted from https://shodhganga.inflibnet.ac.in/bitstream/10603/112671/15/15_appendix\%201.pdf. Ethics in research was taken into consideration by asking permission from the schools where the study was conducted. An ethics committee had also scrutinized the study to check on possible ethical implication of the results. Even though the instrument was adopted, it was translated to the Thai language for better understanding of the respondents and was also subjected to a thorough face validity and reviewed by three (3) experts in the field of education management.

- The data gathered data from the rank and file staff of the IQAN- member Higher Educational Institutions (HELs) in Thailand in the Academic Year 2019-2020. 
- Random sampling was utilized to choose respondents among the rank and file staff of the three institutions.

The focus of the study was on the review of KM status based on the perception of the rank and file staff of the different departments such as the library, IT, laboratory and the different faculties of the IQAN - member HEIs.

- Frequency, percentage and mean values are used in the study to be able to answer the research questions.

\section{Results}

The review of the status of KM was based on the perception of the rank and file staff of the different department such as the library, IT, laboratory and the different colleges/ departments and the secretaries and assistants of the four schools. Tables 1 to 6 describe the general status of KM in the different schools based on the opinion of the above mentioned staff.

Table 1. The data showed that one hundred and twenty four (124, 75.2\%) out of the one hundred and sixty five (165) members of the staff had affirmed that they know about knowledge management and forty one (41, 24.8\%) do not know about knowledge management. This shows that some of the members of the staff have an idea of KM and the others who said they know may not really have an idea that what they are doing is part of KM. The ones who do not know about KM need to be informed about the process. This proves that there in a need to regularly inform the staff.

Table 1. Frequency of the Staff on their Knowledge about KM

\begin{tabular}{lll}
\hline & Frequency & $\%$ \\
\hline Yes & 124 & 75.2 \\
No & 41 & 24.8 \\
\hline
\end{tabular}

Sweeney, J. (2019) supports the idea that employers should send new employees for training and pair new workers with veteran employees, staff members also should have monthly online training in their own specialty and others and employees are asked to share their knowledge with each other.

Table 2. The data showed the opinion of the staff regarding KM. The twenty seven (27, 16.4\%) affirmed that they are doing the processes similar to KM, thirty four $(34,20.61 \%)$ staff members say that KM is a strategic part of the school, ninety $(90,54.55 \%)$ of the staff say that KM is something that could be beneficial for the institution. On the negative side, five $(5,3 \%)$ staff members say that it is just a management fad and nine $(9,5.5 \%)$, other staff say that they never heard about knowledge management. Based on the responses of the staff, a good number of them had a positive opinion on KM. They said that they had been doing it and it is part of the school processes. Most of them say that KM could be beneficial to the institution.

Table 2. Frequency on Opinion about Knowledge Management

\begin{tabular}{lcc}
\hline \multicolumn{1}{c}{ Opinion } & Frequency & $\%$ \\
\hline Something they are already doing but not under the same name & 27 & 16.36 \\
It is a strategic part of the school & 34 & 20.61 \\
Something that could be beneficial for the institution & 90 & 54.55 \\
It is just a management fad. & 5 & 3.03 \\
Never heard about it & 9 & 5.45 \\
Total & 165 & 100
\end{tabular}

According to Bailey \& Clarke (2001), they believe the real relevance of KM is to focus managers on their unique role priority and how to leverage it for organizational benefit.

Table 3. The data showed the perception of the staff if they consider their institution as knowledge based. One hundred and twenty nine $(129,78.2 \%)$ agreed that their institution is knowledge-based institution and nineteen (19, $11.5 \%$ ) do not agree about it but seventeen $(17,10.3 \%)$ do not know if their school is knowledge -based or not. This shows that there is existence of KM process in their institutions. However, it is still essential that the institution should have a program to inform all the staff about the KM processes because a few percent of the staff have negative response and some do not know about KM. The data further shows that the rank and file staff have an idea that their institution practice knowledge management. Those that negated the existence of knowledge management may be those who do not know that there is knowledge management. This shows that these group of employees need to be informed of the existence of the process in the institution. Furthermore, these employees may not have heard 
about the process even if they are practicing it at the moment. If the HEIs will continuously inform their staff, there is better implementation of the process.

Table 3. Opinion if Their HEI is Knowledge-Based

\begin{tabular}{ccc}
\hline Opinion & Frequency & $\%$ \\
\hline YES & 129 & 78.2 \\
NO & 19 & 11.5 \\
I DON'T KNOW & 17 & 10.3 \\
Total & 165 & $10 \%$ \\
\hline
\end{tabular}

Hasani \& Sheikhesmaeili (2016) recommends the managers of higher educational institutions to make their knowledge available for employees to put up as a model. It becomes a culture and employees too share their knowledge with each other to facilitate exchange. It is also recommended to carry out a periodic displacement of people in different parts of substations and transmission of knowledge to facilitate employee empowerment.

The data in table 4 showed that one hundred and six $(106,64.2 \%)$ had an affirmative response which shows that the institutions consider knowledge as an asset and it needs to be managed. However, thirty seven (37, 22.4\%) staff members had negative response which shows that they feel their schools do not consider knowledge as an asset and twenty two $(21,12.73 \%)$ do not have an idea of the situation. It is therefore noticed in the data that a good number of the staff perceived that the schools give importance to knowledge because it is and intangible asset.

Table 4. Knowledge as an Asset

\begin{tabular}{ccc}
\hline opinion & Frequency & $\%$ \\
\hline YES & 106 & 64.2 \\
NO & 37 & 22.4 \\
I DON'T KNOW & 21 & 12.73 \\
Total & 165 & 100 \\
\hline
\end{tabular}

Thomas, G. (1992) corroborates the idea that emerging collaborative paradigm requires that organizations understand fully their knowledge assets and more importantly understand the knowledge that they may not have but required in a given situation.

The data in table 5 showed that the perception on the current status of KM practices in the IQAN member- HEIs. A larger percentage of the staff members rated their institution to be in the growth stage $(68,41.2 \%)$, followed by forty eight $(48,29.1 \%)$ rating their institution to be in the intermediate stage and forty three $(43,26.1 \%)$ to be $n$ the introductory stage. However, six $(6,3.6 \%)$ staff consider that KM is not existent in their institution. This small fraction of the staff who mentioned that $\mathrm{KM}$ is not existent. Maybe these are the uninformed personnel. The assessment of KM by the staff shows that the IQAN institutions to some extent are into KM. However, they still can do improvements on KM processes. Thus, effective knowledge sharing is essential for the universities to take the advantage of the knowledge that academic staff have generated or acquired in order to achieve success.

Table 5. Current Status of KM Practices

\begin{tabular}{lcc}
\hline Opinion & Frequency & $\%$ \\
\hline Not Existent & 6 & 3.64 \\
Introductory Stage & 43 & 26.06 \\
Intermediate Stage & 48 & 29.09 \\
Growth stage & 68 & 41.21 \\
Total & 165 & 100 \\
\hline
\end{tabular}

Pinto (2014) agrees that improvement of knowledge management practices and processes which facilitate an environment and a culture of knowledge collaboration, sharing and discovery should characterize an institution of higher education. At least in this present research, the staff of the IQAN - member universities feel that their institutions are into different stages of KM which maybe dependent on the information that had reached them.

The data in figure 1 showed the ratings of KM practices in the IQAN institutions based on the opinion of their staff. 
The largest percentage of the staff consider the institution to be adequate in their practice and larger percentage of the staff $(72,43.6)$ consider their institution to be good in their practice. However, a small percentage $(14,8.5 \%)$ consider the institutions to have poor practice. And a very negligible number $(3,1.8 \%)$ rated the institutions to have poor practice of KM. The data, however, reveals the existence of KM in the IQAN - member institutions.

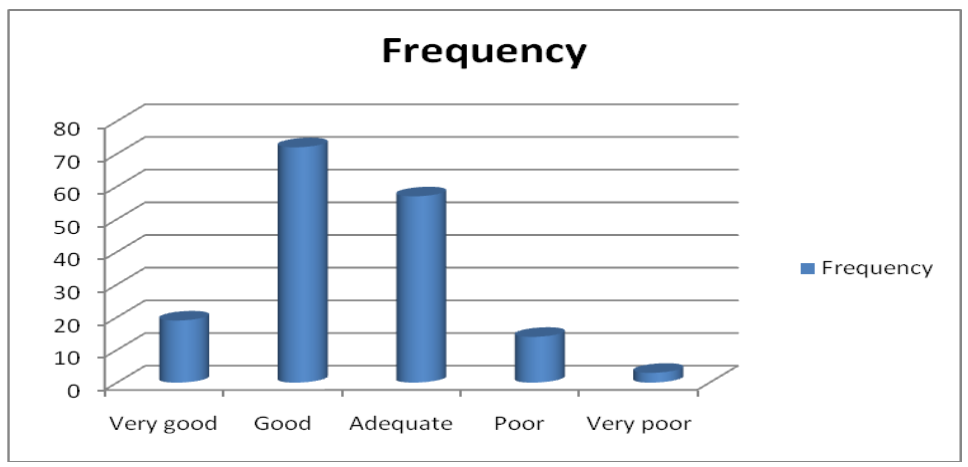

Figure 1. Rating of KM Practice

At least, majority the staff of the IQAN- member HEIs rated their schools from adequate to very good KM practice. In support to this, Oosterlink (2002) pointed out that, in this era of knowledge society and a knowledge economy, it is clear that universities have a major role to play thus given this role, the HEIs should have and intact KM process. In addition, universities are faced with a challenge to better create and disseminate knowledge to society.

Table 6 to 12 show the status of the concrete practices of KM in the IQAN institutions such as knowledge sharing, Knowledge transfer, knowledge storage, knowledge creation, organizational learning and culture.

Table 6 reveals the response of the members of the staff on the indicators of knowledge sharing. The respondents agree or not on the indicators of knowledge sharing. Eighty percent $(136,80 \%)$ of the staff affirmatively responded to the indicators of knowledge sharing but more than twenty eight $(28.75 \%)$ negatively responded. Most of the respondents $(156,94.5 \%)$ have affirmative response that useful knowledge can easily be shared and acted upon in the institutions and the rest negatively responded. Eighty two percent $(147,89.09)$ agrees that is willingness of sharing of experiences and knowledge among people in the workplace. Eighty two percent $(136,82.4 \%)$ say that there are formal channels for knowledge sharing such as meetings, courses, tours, and similar activities. A substantial number of staff $(105,63.63)$ also agrees that there is incentive for knowledge sharing. Those who responded negatively $(28.75 \%)$ may be those who do not know about knowledge sharing or KM as a whole. The result supports the idea of Martensson, M. (2000) that a new paradigm that knowledge must be shared within the organization for growth and development.

Table 6. Knowledge Sharing

\begin{tabular}{|c|c|c|c|c|}
\hline & Ye YES & $\%$ & NO & $\%$ \\
\hline Useful knowledge can be easily shared and acted upon & 156 & 94.5 & 9 & 5.5 \\
\hline $\begin{array}{l}\text { People at workplace share their experiences and knowledge } \\
\text { willingly }\end{array}$ & 147 & 81.9 & 18 & 10.1 \\
\hline $\begin{array}{l}\text { Formal channels for knowledge sharing (like meeting, courses, } \\
\text { tours and similar activities) }\end{array}$ & 136 & 82.4 & 29 & 17.6 \\
\hline Providing incentives for knowledge sharing & 105 & 63.63 & 59 & 37.57 \\
\hline Total & 544 & 322.43 & 115 & 70.77 \\
\hline Mean & 136 & 80.5 & 28.75 & 17.7 \\
\hline
\end{tabular}

The idea of knowledge sharing is supported by Sweeney, J. (2019) who mentioned that employers are to send new employees for training and pairs new workers with veteran employees, staff members also should have monthly online training in their own specialty and others and employees are asked to share their knowledge with each other. In support to the importance of knowledge sharing, Maponya (2000) concluded that people gain knowledge from their experiences and their peers' expertise. Similarly, Ungku Norulkamar \& Amer Hatamleh / Sains Humanika (2014) agrees that knowledge sharing is vital to the success for any organizations, including the universities. 
Universities are knowledge- based organization. Therefore, knowledge sharing is considered as the most important issues for the university.

Furthermore, Fauzi, Nya-Ling, Thursamy, \& Ojo (2019) stated the importance of academics sharing and openly deliver their expertise is needed in all level of academics which include the professors until the junior lecturers and senior lecturers, having academics with the sense of sharing their knowledge without holding any element or component due to self-interest is needed for the sake of institution as a whole.

The data in Table 7 showed that respondents affirm to the fact that there is a well defined process of creation, capturing and acquisition of knowledge, though the employee is given time to access and digest the knowledge, most knowledge is however accessed through other participants like colleagues and associates working with the same institution, which ultimately is not a bad thing in itself but would rather promote collaboration and team work while maintaining the authenticity of the knowledge.

Furthermore, Ungku Norulkamar \& Amer Hatamleh / Sains Humanika (2014) supports the idea that knowledge sharing is vital to the success for any organizations, including the universities. Universities are knowledge- based organization. Therefore, knowledge sharing considered as the most important issues for the university. Thus, effective knowledge sharing is essential for the universities to take the advantage of the knowledge that academic staff have generated or acquired in order to achieve success.

Table 7. Knowledge Transfer

\begin{tabular}{|c|c|c|c|c|c|}
\hline Knowledge Transfer & $\mathrm{Ye}$ & YES & $\%$ & NO & $\%$ \\
\hline $\begin{array}{l}\text { Well defined processes for creation, capture, and } \\
\text { acquisition of knowledge. }\end{array}$ & 117 & & 70.9 & 48 & 29.1 \\
\hline $\begin{array}{l}\text { Much time is taken by an employee to get the } \\
\text { relevant knowledge }\end{array}$ & 108 & & 65.5 & 57 & 34.5 \\
\hline $\begin{array}{l}\text { I trust, give \& take and openness of participants are } \\
\text { key elements for KT }\end{array}$ & 148 & & 89.7 & 17 & 10.3 \\
\hline $\begin{array}{l}\text { I am sure it is feasible that we can learn from each } \\
\text { others knowledge }\end{array}$ & 157 & & 95.2 & 8 & 4.8 \\
\hline
\end{tabular}

According to Garavelli, Gorgoglione, \& Scozzi (2002), if knowledge is successfully materialized into an object such as a Handbook or a Data base. If the object has again to be translated into a competence, it can generate behaviors different from those expected, in many cases, face-to -face communication can be more effective than document exchange, especially when the knowledge actors are culturally different. Furthermore, Blomkvist (2012) mentioned that for a transfer process to have any value for the receiving subsidiary, the received knowledge must be integrated, adopted and used in order to contribute to higher performance. Since the university caters to all stake holders, knowledge created in university through research and teaching should be relevant to the society, and promoting knowledge as a major factor of business of the university and higher education institutions. (Aswath and Gupta, 2009)

Table 8 shows that majority of the rank and file staff perceived that there is documentation and centralization of stored knowledge for easy access across the schools. They also see the importance, relevance of up-to-date knowledge.

Table 8. Storage of Knowledge

\begin{tabular}{lllll}
\hline Knowledge Storage & yes & $\%$ & no & $\%$ \\
\hline Documented procedures centrally stored for ease of access across the school & 123 & 74.5 & 42 & 25.5 \\
Stored knowledge is quite important, relevant and latest & 144 & 87.27 & 21 & 12.72 \\
Do you record of all your informal discussion or meeting? & 97 & 58.8 & 67 & 40.6 \\
\hline
\end{tabular}

Pircher and Pausits (2011) supports the idea that IT infrastructure is an excellent method of storage of knowledge. Information management and the deployment of existing technologies to support the HEI are predominantly driven by administrative rather than management, executive or service-oriented needs. Furthermore, they mentioned that IT infrastructure that adequately handles all the institutional processes and administrative functions is essential for a university to function as an integrated whole, and that also supports strategic decision-making by management. 
Table 9. There is a healthy knowledge creation process in these institutions. The staff respondents believe it is not only the Research and Development department that has the responsibility of creating useful knowledge. As gleaned in table, eighty four percent $(139,84.2 \%)$ affirmatively responded that knowledge creation is actually the duty of everyone, however $80 \%$ of the staff agree that the final decision remain with top management to act in the interest of the organization and also provide support where necessary and similarly, KM is part of the of the organizational philosophy. In addition, the creation and diffusion of knowledge have become ever more important factors in competitiveness (Ikujiro \& Peltokoji, 2006)

Table 9. Knowledge Creation

\begin{tabular}{lcccc}
\hline \multicolumn{1}{c}{ Knowledge Creation } & Ye YES & $\%$ & NO & $\%$ \\
\hline It is the job of R\&D department only & 48 & 29.1 & 117 & 70.9 \\
View as everyone's job and everybody contributes to it & 139 & 84.2 & 28 & 15.8 \\
Top management takes active interest in it and supports it continuously & 132 & 80 & 33 & 20 \\
It is a part of organizational philosophy \& culture & 131 & 79.4 & 34 & 20.6 \\
\hline
\end{tabular}

According to Chou, S. (2005) when the ontology of knowledge creation becomes broader when knowledge creating entities exist from individual organizational level, more knowledge creation process will follow, in order to manage and facilitate knowledge creation effectively, both individual and organizational level activities are important, however, the latter is more important than the former. Dhamdhere (2009) supports the idea that knowledge builds on knowledge and past events helps in generating new knowledge. The main source of generation of knowledge is human efforts which are developed through conducting good educational activities. In support to this. Reid (2000) mentioned that "traditionally, universities have been the sites of knowledge production, storage, dissemination and authorisation". Similarly, Ratcliffe-Martin, Coakes and Sugden (2000) articulated that universities traditionally focus on the acquisition of knowledge and learning.

As gleaned in the table 10, it is evident that administrators are doing pretty well by fostering and encouraging the sharing of individual ideologies, team work and technology training. The institutions are also doing well by encouraging people to participate in a variety of informal learning opportunities, encouraging good communication, teamwork, innovation and lifelong learning. Although, there are areas that can be improved on and that include establishing clear operational guidelines to help staff learning and also the availability of hardware and software technologies to support learning which still need improvement.

Table 10. Organizational Learning

\begin{tabular}{lcccc}
\hline \multicolumn{1}{c}{ Organizational Learning } & YES & $\%$ & NO & $\%$ \\
\hline $\begin{array}{l}\text { Learning organization values supported by formal policy statement and } \\
\text { organization }\end{array}$ & 150 & 90.9 & 15 & 9.1 \\
Encourage people to understand and manage their ideological work & 146 & 88.48 & 19 & 11.52 \\
Encourage people to participate in a variety of informal learning & 148 & 88.5 & 17 & 11.3 \\
opportunities & & & & \\
Establishing clear operational guidelines to help staff learning & 118 & 71.51 & 47 & 28.48 \\
Culture to encourage good communication, teamwork, innovation and & 135 & 81.8 & 30 & 18.2 \\
lifelong learning & & & & \\
Hardware and software technologies are available to support learning & 128 & 78.8 & 36 & 21.8 \\
\hline
\end{tabular}

Pentland (2005) had emphasized in his research that traditional approaches to organizational learning have emphasized the ways in which information systems can lower the costs and increase capacity for search, storage, and retrieval of information. This supports the idea that learning organizational values are essential in knowledge management. According to Intezari, Taskin, \& Pauleen (2017), at the organizational level, the cultural aspect is more concerned with management's support and involvement, whether or not individuals and groups are rewarded for their active role in knowledge process, as well as the extent to which mistakes are acceptable and people in the organization are given the freedom to exercise new practices.

Table 11. The knowledge management culture in these institutions are seen to be effective as it is, knowledge sharing and learning is valued though respondents believe a virtual platform where people can contact each other is a more preferable option. 
Table 11. Culture

\begin{tabular}{lcccc}
\hline Culture & yes & $\%$ & No & $\%$ \\
\hline Corporate culture affects retention & 149 & 90.3 & 18 & 9.7 \\
Knowledge sharing and learning are valued in my company culture & 137 & 83 & 28 & 17 \\
A virtual platform where people can contact each other is a suitable option & 144 & 87.5 & 21 & 12.7 \\
\hline
\end{tabular}

According to Bennett (2009), organizations way of using information vary from one culture to another even in the same industry because it is usually based on cultural values which usually makes organisational change so difficult. Further, Charles and Nawi (2017) stressed that KM should be an integral part of the organizational culture. White (2014) supports the idea that virtual teams can be very effective way of bringing together the most appropriate set of skills and experiences in order to meet business objectives without the cost of logistical problems of having a team of employees come together around the same table on a regular basis.

Table 12 shows the preference of the usage of technology in knowledge management. It was discovered that staffs of the aforementioned universities used in the course of this study would rather prefer to use community of practices as a technology for knowledge management, followed by data danagement and e-mails. This reveals that some rank and file staff are not much into the use of technology in managing knowledge. The IQAN HEIs need to have a review of their KM practices to be able to find out areas to improve. Since there is willingness of some rank and file staff in the usage of technology in the KM process therefore, the organization should encourage the usage of technology by informing their people about available technologies and how to use these resources. This is supported by Chourides, Longbottom, \& Murhy (2003) wherein they mentioned that if strategy and people are the principal drivers of KM then it can be argued that IT is a fundamental enabler and essential part of modern organizations.

Table 12. Usage of Technology Knowledge Management

\begin{tabular}{|c|c|c|c|c|c|c|c|}
\hline & $\begin{array}{c}\text { Strongly } \\
\text { preferred } \\
(\mathrm{SP})\end{array}$ & $\begin{array}{l}\text { Preferred } \\
\text { (p) }\end{array}$ & $\begin{array}{l}\text { Neutral } \\
(\mathrm{N})\end{array}$ & $\begin{array}{l}\text { Least } \\
\text { Preferred } \\
(\mathrm{LP}) \\
\end{array}$ & $\begin{array}{l}\text { Very least } \\
\text { Preferred } \\
(\mathrm{VLP})\end{array}$ & Mean & Stdev \\
\hline Internet & 35 & 10 & 16 & 37 & 67 & $2.4485 \mathrm{LP}$ & 1.57 \\
\hline Intranet & 16 & 17 & 52 & 43 & 27 & $2.7091 \mathrm{LP}$ & 1.15 \\
\hline $\begin{array}{l}\text { Customer relationship } \\
\text { management }\end{array}$ & 14 & 11 & 75 & 44 & 21 & $2.7152 \mathrm{LP}$ & 1.05 \\
\hline $\begin{array}{l}\text { Management } \\
\text { Information System }\end{array}$ & 16 & 29 & 21 & 57 & 42 & $2.5152 \mathrm{LP}$ & 1.31 \\
\hline Expert Networks & 15 & 28 & 46 & 54 & 22 & $2.7576 \mathrm{LP}$ & 1.16 \\
\hline E-mail & 44 & 5 & 21 & 44 & 51 & $2.6788 \mathrm{LP}$ & 1.59 \\
\hline Video conferencing & 31 & 24 & 49 & 40 & 53 & $2.9939 \mathrm{LP}$ & 1.28 \\
\hline Data warehousing & 17 & 31 & 35 & 52 & 34 & $2.7030 \mathrm{LP}$ & 1.27 \\
\hline Browsers & 22 & 29 & 28 & 52 & 34 & $2.7152 \mathrm{LP}$ & 1.33 \\
\hline Content Management & 24 & 34 & 28 & 38 & 31 & $2.8909 \mathrm{LP}$ & 1.33 \\
\hline Knowledge Portals & 24 & 25 & 24 & 58 & 34 & $2.6788 \mathrm{LP}$ & 1.35 \\
\hline Data support system & 27 & 21 & 32 & 53 & 32 & $2.7455 \mathrm{LP}$ & 1.35 \\
\hline Information Technology & 31 & 22 & 16 & 44 & 52 & $2.6121 \mathrm{LP}$ & 1.51 \\
\hline E- Learning & 17 & 36 & 29 & 46 & 38 & $2.6848 \mathrm{LP}$ & 1.32 \\
\hline Groupware & 17 & 31 & 50 & 49 & 18 & $2.8788 \mathrm{LP}$ & 1.15 \\
\hline $\begin{array}{l}\text { Data management } \\
\text { system }\end{array}$ & 16 & 44 & 32 & 37 & 36 & $2.8000 \mathrm{LP}$ & 1.31 \\
\hline Community of Practices & 20 & 48 & 37 & 34 & 26 & $3.0121 \mathrm{~N}$ & 1.27 \\
\hline Story Telling & 21 & 38 & 57 & 37 & 12 & $3.1152 \mathrm{~N}$ & 1.12 \\
\hline $\begin{array}{l}\text { Likert scale: } 1-1.99 \text { (VLP) } \\
\text { 5- } 5.99(\mathrm{SP})\end{array}$ & $2-2.99$ & (LP) 3-3.9 & $(\mathrm{N})$ & $99(\mathrm{P})$ & Grand Mean & $2.72 \quad(\mathrm{LP})$ & \\
\hline
\end{tabular}

\section{Discussion}

Knowledge management $(\mathrm{KM})$ is cultural in nature. Thai culture is intact and it influenced the response to the integration of western management concepts that were introduced into Thailand for the past years. Many of these 
concepts were not applied but there were evidences of the inclusion of some western concepts in management of organizations with some of them not successfully implemented since the Thai culture is different from western culture. Without its understanding, academics and practitioners might lose their way to the successful implementation of western management concepts. There are some Thai values that maybe difficult to understand by foreign people. A few are mentioned in the succeeding discussions.

Rohitratana (2003) mentioned that Thai employees believe that their bosses or employers have the wisdom knowledge and experience which surpass their own capacity. The structure of the organizations in Thailand is highly hierarchical so the employees will wait for the dictate from their bosses. They usually wait for the information from higher ups. In other cultures, this situation is uncommon, rank and file staff normally will ask from their bosses on what is happening in the organization. This culture bound behavior may be the reason that some of the rank and file employees had negated the existence of the processes of KM because they are just waiting for information from their boss. Thai people believe that it is a requirement to follow superior's instruction because they believe that decisions should come from top management. So to adjust to these values, managers should see the necessity of communicating knowledge management processes to the rank and file staff. Rohitrana (2003) further emphasized that saving face value is widely applicable to most organizations in Thailand thus protecting the person involved when there is a problem is the most important thing to do. Saving face may hinder KM implementation because people do not usually get advice from others. In KM process, collaboration and peer assessment is essential. "Kreng jai" is another Thai value which foreigners often find difficult to understand. Komin (1990) and Holmes and Tantongavy (1996) defined it as the situation where there was the potential for discomfort or conflict but an individual tried to take another person's feelings into account. This again hinders development because Thai people may avoid peer evaluation instead of correcting the person, they feel it is not appropriate to tell what should be done. In Thailand, this behavior has been established for several decades and it becomes a root of social system which is widely applied everywhere.

Bunyagidj, et al. (2003) agreed with the other researchers and suggested that knowledge-sharing culture was essential to the success of KM implementation in Thailand. However, majority of Thai organizations did not pay much attention to such culture. The strong seniority culture, where the junior did not dare to speak out in front of the senior, was still considered as normal practice in Thai society. Thus, learning, which embraces the acquisition of existing and the development of new knowledge in order to improve organizational performance, can be hindered.

Petrides and Nodine (2003) added that, knowledge management in higher educational institutions could help the institution in reviewing, revising, and effecting stronger curriculum development processes, interdepartmental assessments, department portfolios or program reviews, however, most significant is that, everyone should be willing to inform and be informed all the time

Another factor that may affect KM is the technology infrastructure, an essential tool in KM process. Information technology has caused a major paradigm shift in the way information services are delivered. Even though organizations cannot achieve the implementation of a KM with technology alone, infrastructure, specifically IT, is required to obtain available information. It provides easy access to information and the knowledge resources with minimum time frame. Southeast Asian countries are trying to catch up with their more advanced counterparts in terms of the information infrastructure. It is believed, however, that IT will permit more efficient decision making and improve the country's competitiveness. Lim (1999) mentioned that the state of R\&D, these countries are still far way behind compared with the developed countries. In Thailand, the rapid economic growth rate allowed an increasing number of Thai citizens to enjoy ready access to subsidized utilities that were monopolistically operated by Thai state enterprises (SE). Comparing to other developing countries, Thailand's infrastructure is not much developed. However, with the advent of the Thailand 4.0 national program, ICT was given more attention. These situations still hinder the full implementation of KM in organizations including the academe which may explain the proportion who negated presence of KM in the IQAN- member HEIs in Thailand.

In addition, Thailand also has the problem of the low level of computer literacy and low level of access to computers required for information processing as revealed by the International Telecommunication Union (ITU) in 2003 (www.itu.int). ITU initiated the first global index to rank Information and Communication Technology (ICT) access called Digital Access Index (DAI) which covered a total of 178 economies. The index covered variables in five areas, namely the availability of infrastructure, affordability of access, educational level, quality of ICT service, and Internet usage. According to the DAI, Thailand was categorized as a medium access country and had a score of 48/100. If this data had improved, this is still behind compared to more advanced economies. However, the HEIs under study are private organizations which may better in terms of IT infrastructure. This may be the reason why 
most of the rank and file staff affirmed the existence of the processes of KM because they have easy access to stored information and creation of knowledge may be available at a certain point. Lau and Tsui (2009) supports that KM and knowledge sharing tools such as search engines, internet, intranet and peer to peer knowledge tools, are essential within the learning environment. Such tools help them to share their interest, information and knowledge to create new knowledge. This supports that IT infrastructure is essential.

\section{Conclusion}

Based on the results of the study, the following conclusions were made. KM is existent at a certain point in these HEIs but still at its developing stage hence, KM is still at moderate level among IQAN- member HEIs in Thaland. Rank and file staff affirmed that they were also familiar with the process of KM and they believed it is an essential part of the organization which they also consider as beneficial. They also further believed that knowledge is an asset and need to be managed and more importantly be created, stored, communicated, applied and reviewed for continuous development. In addition, they perceived that everyone in the organization has a role to play in the KM process and teamwork is essential. They also perceived that the provision of incentives to the creation of knowledge is essential. Also, they also affirmed that there are informal and formal sharing of knowledge among teams especially among those working in the same field. IT infrastructure is believed by the rank and file staff as essential and they felt that there is a need to improve this part of KM process.

\section{Recommendation}

The following suggestions for the improvement of the KM process in the IQAN - member HEIs are the following:

- Working by teams is an easier way to manage KM because those with the same expertise understand each other better that is why in the rank and file staff in this research preferred communities of practice as a technology tool to use in KM.

- As an integral part of KM, knowledge sharing can be regularly done. This can be exemplified by publishing research output and sharing it in an organized research congress among the researchers of the HEIs not only within one institution but among the IQAN-member college and universities. This can enhance the process so that rank and file staff will be involved in the KM endeavor.

Use of ICT to enhance and facilitate Knowledge Management (KM) has brought to focus the urgent need to come out with new methods, tools and techniques in the development of KM systems frameworks, knowledge processes and knowledge technologies to promote effective management of knowledge for improved service deliveries in higher education. (Umuna, W and van der Weide, T.)

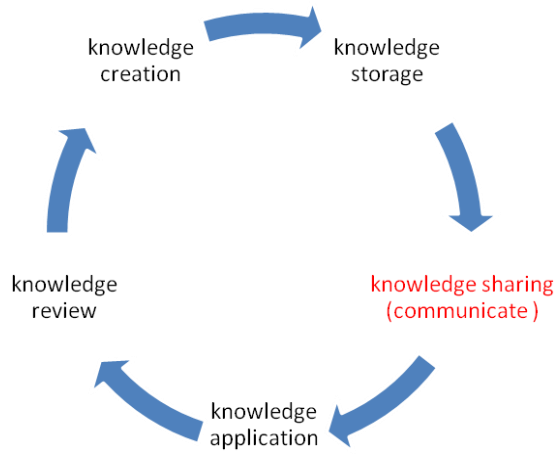

Figure 2. Knowledge Management Process in Educational Institution

\section{Acknowledgement}

The author would like to express her gratitude to the IQAN- member HEIs of Thailand namely: St. Theresa International College, Stamford University, Rangsit University and Asia-Pacific University as venue for the 
Research and the thesis committee of St. Theresa International College for the invaluable contributions in the improvement of this thesis.

\section{References}

Alavi, M., \& Leidner, D. E. (2001). Review: Knowledge management and knowledge management systems: Conceptual Foundations and Research Issues. MIS Quarterly, 25(1) (Mar., 2001), 107-136. Management Information Systems Research Center, University of Minnesota. https://doi.org/10.2307/3250961

Aswath, L., \& Gupta, S. (2009). Knowledge management tools and academic library services. Proceedings of the International Conference on Academic Libraries (ICAL 2009) (pp. 05-08). Delhi, India. Retrieved from http://crl.du.ac.in/ical09/papers/index_files/ical-31_249_724_1_RV.pdf

Atkočiūnienè, Z., \& Praspaliauskytè, G. (2018). The influence of intellectual capital and knowledge management on organizational performance in Lithuanian Software Companies. Ekonomika (Economics), 97(2), 106-120. https://doi.org/10.15388/ekon.2018.1.11789

Bailey, C., \& Clarke, M. (2001). Managing knowledge for personal and organisational benefit. Journal of Knowledge Management, 5(1), 58-68.

Biloslavo, R., \& Trnavcevic. (2007). A knowledge management audit in a higher educational Institution: A Case Study. Knowledge and Process Management, 14(4) 275-286. https://doi.org/10.1002/kpm.293

Blomkvist, K. (2012). Knowledge management in MNCs: the importance of subsidiary transfer performance. Journal of Knowledge Management, 16(6), 904-918. https://doi.org/10.1108/13673271211276182

Bunyagidj, B., Prasopsukchokchai, N., Pornchanoknart, D., \& Karnluan, P. (2003). Thailand Experience: Pilot Project on KM Implementation Paper presented at The 3rd European Knowledge Management Summer School on 7-12 September 2003, San Sebastian: Spain.

Charles, W., \& Nawe, J. (2017). Knowledge management (KM) practices in institutions of higher learning in Tanzania with reference to Mbeya University of Science and Technology, 61. EISSN: 0856-1818 Retrieved from https://www.ajol.info/index.php/udslj/article/download

Chou, S. (2005). Knowledge creation: absorptive capacity, organizational mechanisms, and knowledge storage/retrieval capabilities. Journal of Information Science, 31(6), 453-465. https://doi.org/10.1177\%2F0165551505057005

Chourides, P., Longbottom, D., \& Murhy, W. (2003). Excellence in knowledge management: An empirical study to identify critical factors and performance measures. Measuring Business Excellence, 7(2), 29-45. https://doi.org/10.1108/1368304031047797767

Dasgupta, H. (2011). Data mining techniques in knowledge management. Enhancing academic research with knowledge management principles. (eds. Deshpande, D. S, et al). https://doi.org/10.4018/978-1-2459-2 ch008

Dhamdhere, S. N. (2015). Knowledge management model for higher educational institutes. Journal of Commerce and Management Thought, 6(1), 130-161. https://doi.org/10.5958/0976-478x.2015.00010.5

Fauzi, M., Nya-Ling, C., Thursamy, R., \& Ojo, A. (2019). Knowledge sharing. VINE Journal of Information and Knowledge Management Systems, 49(1), 136-159. Gartner Group Glossary. Retrieved from www.gartner.com

Garavelli, A., Gorgoglione, M., \& Scozzi, B. (2002). Managing knowledge transfer by knowledge technologies. Tecfrohnovation, 22(5), 269-279.

Girard, J. P., \& Girard, J. L. (2015). Defining knowledge management: Toward an applied compendium. Online Journal of Applied Knowledge Management, 3(1), 1-20.

Gupta, B., Iyer, S. L., \& Aronson, E. J. (2000). Knowledge management: practices and challenges. Industrial Management \& Data Systems, 100(1), 17-21. http://dx.doi.org/10.1108/02635570010273018

Hasani, K., \& Sheikhesmaeili, S. (2016). Knowledge management and employee empowerment. Kybernetes, 45(2), 337-355. https://doi.org/10.1108/K-04-2014-0077

Hassandoust, F., Logeswaran, R., \& Kazerouni, M. F. (2011). Behavioral factors influencing virtual knowledge sharing: theory of reasoned action. Journal of Applied Research in Higher Education, 3(2), 116-134. Emerald Group Publishing. 
Hawkins, B. (2000). Libraries, Knowledge Management, and Higher Education in an Electronic Environment, 26. Retrieved from http://www.alia.org.au/conferences/alia2000/proceedings/bria n.hawkins.html.

Holmes, H., \& Tangtongtavy, S. (1996). Working with the Thais: A Guide to Managing in Thailand. Bangkok: White Lotus.

Huang, K. (1998). Capitalizing on intellectual assets. IBM Systems Journal, 37, 0-584.

Inkinen, H. T., Kianto, A., Vanhala, M. (2015). Knowledge management practices and innovation performance in Finland. Baltic Journal of Management, 10(4), 432.

Intezari, A., Taskin, N., \& Pauleen, D. (2017). Looking beyond knowledge sharing: an integrative approach to knowledge management culture. Journal of Knowledge Management, 21(2), $492-515$. https://doi.org/10.1108/JKM-06-2016-0216

Kidwell, J. J., Vander Linder, K. M., \& Johnson, S. L. (2004). Applying corporate knowledge management practices in higher education. Educause Quarterly, 4, 28-33.

Komin, S. (1990). Culture and work -related values in the Thai Organization. International Journal of Psychology, 25(36), 569-595. https://doi.org/10.1080/00207599008247921

Lau, A., \& Tsui, E. (2009). Knowledge management perspective on e-learning effectiveness. Knowledge based systems, 22(4), 324-325. http://dx.doi.org/10.1016\%2Fj.knosys.2009.02.014

Lim, D. H. (2007). Organizational and cultural factors affecting international transfer of training. Performance Improvement, 07 February, 2007. Wiley Persiodcals Incorporated. https://doi.org/10.1002/pfi.4140380309

Madhar, M. A. (2010). Knowledge Management in higher educational institutions with special reference to College of Applied Sciences (CAS). Ministry of Higher Education, Sultanate of Oman. https://dx.doi.org/10.2139/ssrn.1663543

Maponya, P. M. (2004). Knowledge management practices in academic libraries: a case study of the University of Natal, Pietermaritzburg Libraries. Information Studies Programme, School of Human and Social Studies, University of KwaZulu-Natal, Pietermaritzburg, South Africa Academia.edu. Retrieved 11 December, 2019.

Martensson, M. (2000). A critical review of knowledge management as a management tool. Journal of Knowledge Management, 4(3), 204-216.

Mládková, L. (2011). Knowledge management for knowledge workers. University of Economics Prague, Czech Republic: Academic Publishing International Ltd, 248-258.

Nonaka, I., \& Peltokoji. V. (2006). Objectivity and subjectivity in knowledge management: A review of 20 top articles. Knowledge .and Process Management, 13(2), 73-82. https://dx.doi.org/10.1002/kpm.251

None (2015). Knowledge management and business strategy: Communities of practice can give you that competitive edge. Strategic Direction, 31(9), 25-28. https://doi.org/10.1108/SD-07-2015-0098

Omona, W., van der Weide, T., \& Lubega, J. (2010). Using ICT to enhance Knowledge Management in higher education: A conceptual framework and research agenda. International Journal of Education and Development using ICT, 6(4), 83-101.

Oosterlink, A. (2002). Knowledge management in post-secondary education: universities. Retrieved from http://www.oecd.org/pdf/M00027000/M00027356.pdf

Pentland, B. T. (1995). Information systems and organizational Learning: The social epistemology of organizational knowledge systems. Accounting, Management and Information Technologies, 5(1), 1-21. https://doi.org/10.1016/0959-8022(95)90011-X

Petrides, A. L., \& Nodine, R. T. (2003). Knowledge management in education: defining the landscape. The institution for the study of knowledge management in education Press, USA. Retrieved from http://iskme.path.net/kmeducation.pdf

Pinto, M. (2014). Knowledge management in higher education institutions: A framework to improve collaboration. Iberian Conference on Information Systems and Technologies. IEEE. Barcelona, Spain. https://dx.doi.org/10.1109/CISTI.2014.6876876

Pircher \& Pausits (2011). Information and knowledge management at higher education institutions. Management Information Systems, 6(2), 8-16. 
Ramakrishnan, K., \& Yasin, N. M. (2012). Knowledge management system and higher education institutions. International Conference on Information and Network Technology (ICINT 2012) IPCSIT, 37, IACSIT Press, Singapore. Retrieved from http://www.ipcsit.com/vol37/013-ICINT2012-I072.pdf

Ratcliffe-Martin, V., Coakes, E., \& Sugden, S. (2000). Knowledge Management issues in universities. VINE, 30(4), 14-18. https://doi.org/10.1108/eb040770

Reid, I. C. (2000). The web, knowledge management and universities. AusWeb2k-The Sixth Australian World Wide Web Conference, 12-17. 2000/6/12. Retrieved from http://ausweb.scu.edu.au/aw2k/papers/reid/

Rohitratana, K. (2003). How to use the interview as an effective tool to conduct qualitative research in the Asian organizational context. Papers presented at The 2nd European Conference on Research Methodology for Business and Management on 20-21 March, 2003. 295-302. Academic Conferences Limited Reading, United Kingdom, International Journal of Educational Management.

Rowley, J. (2000). Is higher education ready for knowledge management. International Journal of Educational Management, 14(7), 325-333. https://doi.org/10.1108/09513540010378978

Sweeney, J. (2019). How to survive staff shortages. Medical Economics, 96(9), 0-0.

Thomas, G. (1992). Knowledge as an asset - a view from industry. Journal of Computer Assisted Learning, 8(3), 131-135. https://doi.org/10.1111/j.1365-2729.1992.tb00398.x

Ungku Norulkamar, Amer Hatamleh, \& Sains Humanika. (2014). A review of knowledge sharing barriers among academic staff: A Malaysian perspective, 87-91, indexed by MyJurnal. Retrieved from www.itu.int

White, M. (2014). Managing virtual teams and virtual meetings. Business Information Review, 31(2), 111-117. https://doi.org/10.1177\%2F0266382114540979

\section{Copyrights}

Copyright for this article is retained by the author(s), with first publication rights granted to the journal.

This is an open-access article distributed under the terms and conditions of the Creative Commons Attribution license (http://creativecommons.org/licenses/by/4.0/). 